
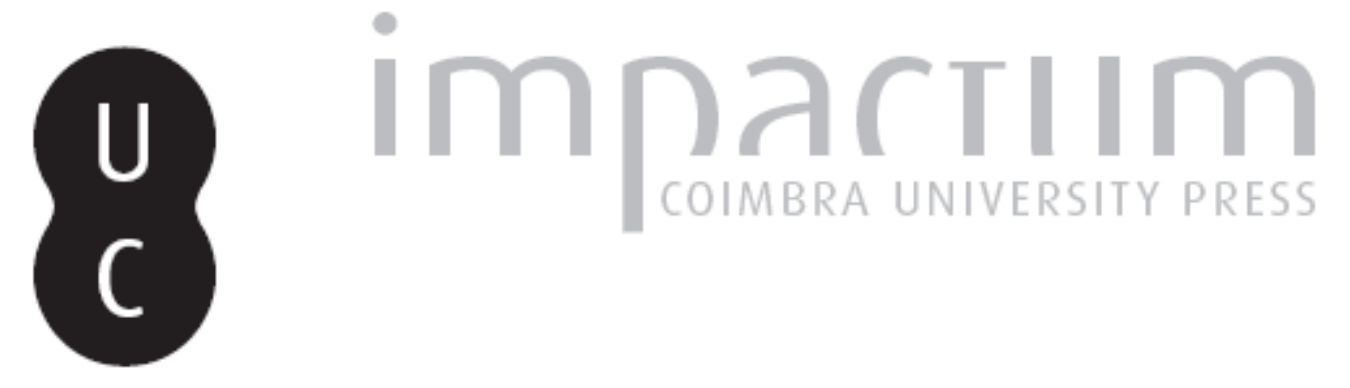

Uma estatueta funerária egípcia no Museu de Aveiro

Autor(es): $\quad$ Araújo, Luís Manuel

Publicado por: Centro de História da Universidade de Lisboa

URL persistente:

URI:http://hdl.handle.net/10316.2/23845

DOI:

DOI:http://dx.doi.org/10.14195/0871-9527_18_12

Accessed : $\quad$ 26-Apr-2023 11:50:40

A navegação consulta e descarregamento dos títulos inseridos nas Bibliotecas Digitais UC Digitalis, UC Pombalina e UC Impactum, pressupõem a aceitação plena e sem reservas dos Termos e Condições de Uso destas Bibliotecas Digitais, disponíveis em https://digitalis.uc.pt/pt-pt/termos.

Conforme exposto nos referidos Termos e Condições de Uso, o descarregamento de títulos de acesso restrito requer uma licença válida de autorização devendo o utilizador aceder ao(s) documento(s) a partir de um endereço de IP da instituição detentora da supramencionada licença.

Ao utilizador é apenas permitido o descarregamento para uso pessoal, pelo que o emprego do(s) título(s) descarregado(s) para outro fim, designadamente comercial, carece de autorização do respetivo autor ou editor da obra.

Na medida em que todas as obras da UC Digitalis se encontram protegidas pelo Código do Direito de Autor e Direitos Conexos e demais legislação aplicável, toda a cópia, parcial ou total, deste documento, nos casos em que é legalmente admitida, deverá conter ou fazer-se acompanhar por este aviso.

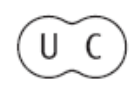



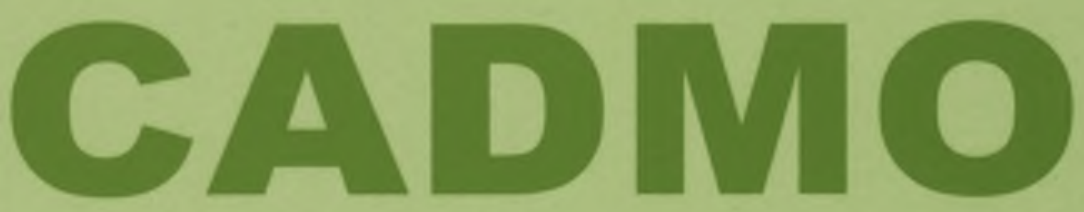

Revista de História Antiga

\author{
Centro de História \\ da Universidade de Lisboa
}

18

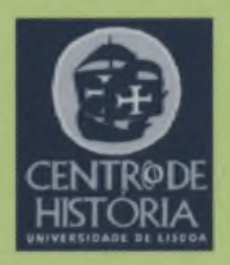

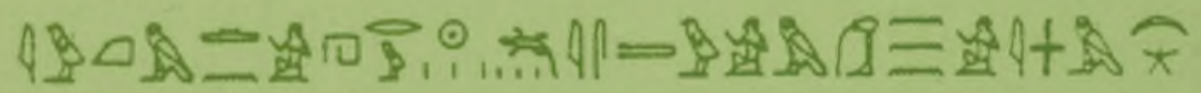

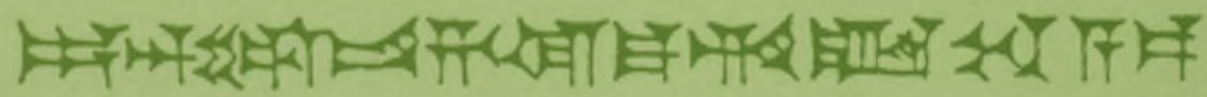

MHNIN AEI $\Delta$ E $\Theta E A ~ \Pi H \Lambda H I A \triangle E \Omega$ 


\section{UMA ESTATUETA FUNERÁRIA EGÍPCIA NO MUSEU DE AVEIRO}

Por amável informação da directora do Museu de Aveiro, Dra. Ana Margarida Serra Ferreira, a quem muito agradecemos, tomámos conhecimento da existência de uma estatueta funerária egípcia com inscrição hieroglífica frontal. A imagem da referida peça foi enviada por via electrónica, e é ela que neste artigo se reproduz, na página seguinte, com visão frontal e lateral.

O Museu de Aveiro (ou Museu de Santa Joana Princesa) alberga uma importante colecção de arte sacra, mas também possui um pequeno núcleo arqueológico que integra a estatueta funerária egípcia que aqui divulgamos, sem que se saiba como foi ela lá parar. Aliás, este é um fenómeno comum a outras colecções, nomeadamente a colecção egípcia do Museu Nacional de Arqueologia, a maior do nosso país (com cerca de trezentos objectos expostos e outros tantos nas reservas), que inclui vários objectos de proveniência desconhecida.

A figurinha é feita de terracota pintada de verde exibindo ligeiro brilho em certas partes da superfície (mão direita que empunha o chicote e parte do avental). Está partida pelos joelhos, na base do saiote e do avental, tendo sido colada. As pernas e os pés estão sumariamente indicados, assentes numa pequena base, e a parte de trás é lisa. A altura da peça é de $11,4 \mathrm{~cm}$.

A maior parte das estatuetas funerárias, conhecidas pela designação de chauabtis ou uchebtis, tem um aspecto mumiforme, pois representam a miniaturização do corpo mumificado do defunto evocando, ao mesmo tempo, o trabalhador que no Além iria desempenhar as míticas actividades agrícolas que o aguardavam nos campos de Osíris. A partir do pontificado do sumo sacerdote Pinedjem II (c. 990-969 a. C.), já em finais da XXI dinastia, o termo chauabti será gradualmente substituído por uchebti, derivado do verbo ucheb (responder). Enfim, esperava-se que as diligentes estatuetas funerárias respondessem à chamada em lugar do morto quando este fosse convocado 

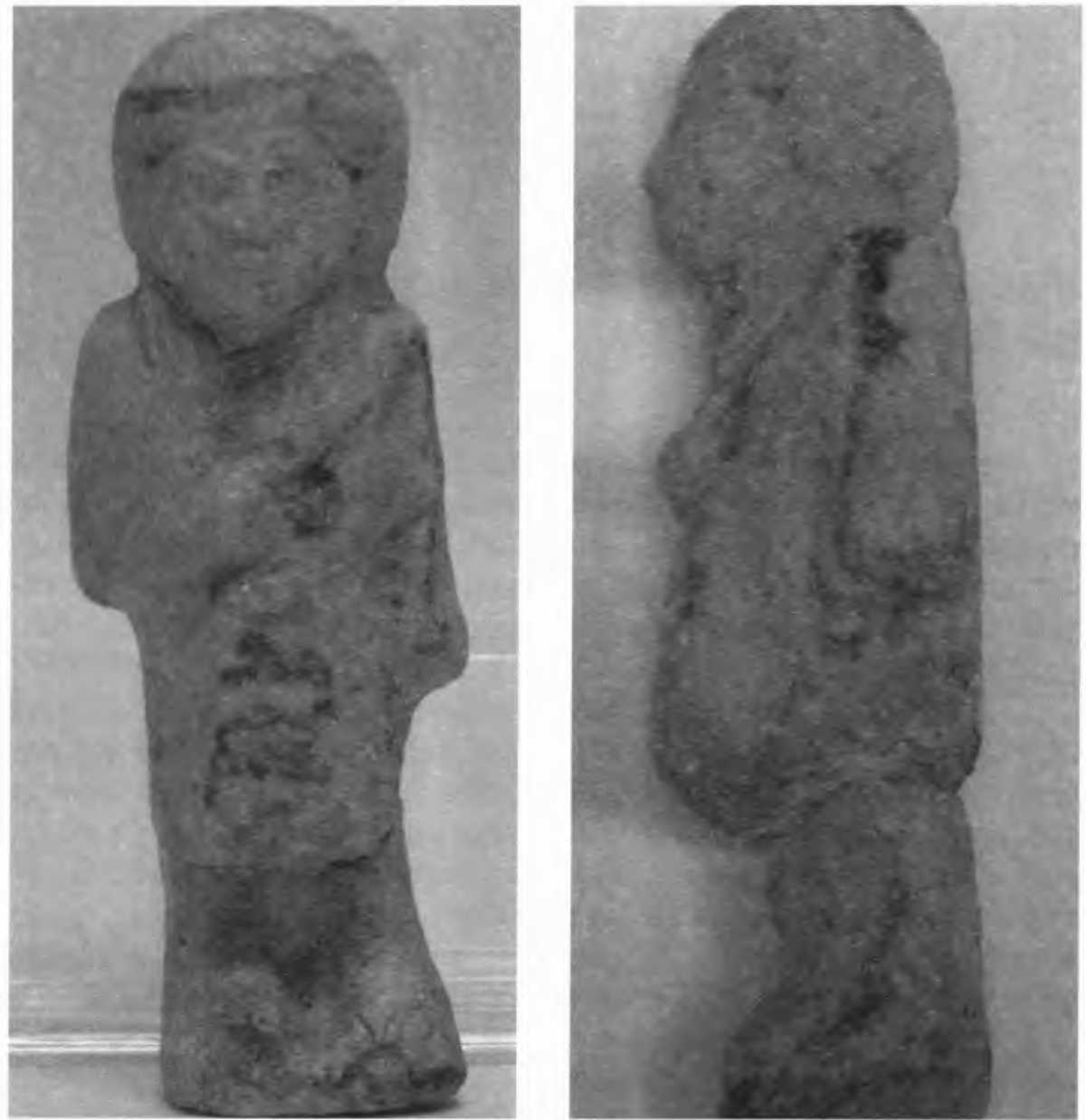

A estatueta funerária egípcia do Museu de Aveiro, vista de frente (com a tosca inscrição hieroglífica no saiote) e de lado.

para a faina agrícola no outro mundo. Acontece que a ordem e a disciplina laboral existente na vida terrena se reproduzia no Além, e por isso cada grupo de dez estatuetas mumiformes era liderado por um capataz, representado por uma figurinha que não se apresentava como uma múmia mas sim com um saiote - e alguns mais requintados podiam exibir avental, sandálias e cabeleiras mais cuidadas.

As figurinhas de capatazes começaram a aparecer durante o reinado de Ramsés II (XIX dinastia), e aumentaram de número ao longo 
da XXI dinastia, para depois virem a desaparecer dos espólios fúnebres a partir da XXVI dinastia. Que um capataz chefiava um grupo de dez trabalhadores vê-se bem pela habitual designação egípcia do cargo: aá en medu, isto é, o "grande dos dez". Em francês tem aparecido a forma dizenier ou chef dizenier, a par de chef ou contremaître, enquanto os egiptólogos anglo-saxónicos optam por overseer e os alemães por Aufseher, entre outras formas.

Assim, a presente estatueta funerária é um capataz, exibindo por isso mesmo um chicote a atestar a sua autoridade e não os alviões típicos das estatuetas mumiformes. A cabeça é envolvida por uma cabeleira arredondada, que cobre as orelhas e tem uma fita preta atada atrás com um laço, como é tradicional nas estatuetas funerárias produzidas a partir de inícios da XXI dinastia (pontificado do sumo sacerdote Masaharta, c. 1050 a. C.) e que iria continuar a ser usada ao longo da XXII dinastia. A fita preta no cabelo atada atrás é pois um elemento iconográfico que permite datar esta estatueta.

A parte da cabeleira que cai sobre os ombros mostra finas madeixas de cada lado do rosto, o qual está bastante erodido, mal se notando já os olhos, o nariz achatado e a boca. Os olhos estão assinalados com dois pontos negros esmaecidos e da boca subsiste uma leve incisão horizontal.

O braço esquerdo está caído ao longo do corpo, estando o direito flectido com a mão junto ao peito segurando um chicote pintado de preto que sobe até ao ombro e cai acompanhando o braço esquerdo.

Como é próprio das figuras que representam capatazes, tem saiote e avental à frente, de forma trapezoidal, onde foi pintada a preto uma inscrição vertical com hieróglifos cursivos que se lêem com dificuldade. A inscrição inicia-se com o típico título-nome de Osíris, seguido pelo nome do defunto, que parece ser Djedmut, com a tradução de "(A deusa) Mut diz" ou "A (deusa) Mut fala".

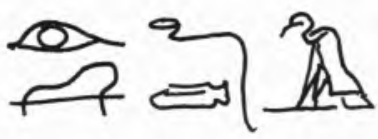

Wsir $\underline{D} d-M w t$ (Osíris Djedmut)

Esta forma onomástica é uma redução de formas mais completas, amiúde usadas na XXI e XXII dinastias, como Djedmutiuesankh ("Mut diz que ela está viva») ou Djedmutiuefankh («Mut diz que ele está vivo"). Em colecções egípcias existentes no nosso país não se encontram estes dois nomes, nem a forma abreviada de Djedmut, embora se detectem nomes de construção idêntica invocando Maet, Tot 
e Khonsu (colecções do Museu Nacional de Arqueologia e Sociedade de Geografia de Lisboa, e colecção privada de Miguel Barbosa).

O nome de Djedmut remete-nos para a necrópole de Deir el-Medina, em Lucsor Ocidental, mais precisamente para os poços $10 \mathrm{e}$ 10B, onde Bernard Bruyère, então ao serviço do Institut Français d'Archéologie Orientale, descobriu nos anos vinte do século passado algumas dezenas de figurinhas pertencentes a duas personagens ali inumadas: Khonsuhotep e Djedmut (desconhece-se se eram familiares). Dominique Valbelle viria depois a publicar a lista das estatuetas funerárias encontradas em vários poços e túmulos de Deir el-Medina (Ouchebtis de Deir el-Médineh, Cairo: IFAO, 1972), e lá constam os exemplares feitos para Khonsuhotep e Djedmut.

É provável que esta estatueta seja oriunda desse local muito frequentado desde o Império Novo, e que durante o Terceiro Período Intermediário serviu para lá sepultar vários funcionários tebanos e seus familiares. Desconhece-se em que circunstância esta estatueta, hoje no Museu de Aveiro, chegou à Europa e, mais estranho ainda, a Portugal.

\section{Bibliografia}

Luís Manuel de ARAÚJO, Estatuetas Funerárias Egípcias da XXI dinastia, Lisboa: Fundação Calouste Gulbenkian e Fundação para a Ciência e a Tecnologia, 2003

J.-F. AUBERT e Liliane AUBERT, Statuettes Égyptiennes. Chaouabtis, Ouchebtis, Paris: Librairie d'Amérique et d'Orient Adrien Maisonneuve, 1974

Jean-Luc BOVOT, "Les figurines funèraires du Louvre provenant de la Cachette Royale (DB 320)", em Egypte, Afrique \& Orient, 38, Juin 2005, pp. 13-34

Hermann RANKE, Die Ägyptischen Personennamen, I, Glückstadt: Verlag J. J. Augustin, 1935

Hans SCHNEIDER, Sbabtis. An Introduction to the History of Ancient Egyptian

Funerary Statuettes with a Catalogue of the Collection of Antiquities at

Leiden, 3 volumes, Leiden: Rijksmuseum van Oudheden te Leiden, 1987

Dominique VALBELLE, Ouchebtis de Deir el-Médineh, Cairo: IFAO, 1972

Luís Manuel de Araújo 